\title{
Population growth of northern anchovy and Pacific sardine using stage-specific matrix models
}

\author{
Nancy C. H. Lo*, Paul E. Smith, John L. Butler \\ Southwest Fisheries Science Center, PO Box 271, La Jolla, California 92038, USA
}

\begin{abstract}
We applied a stage-specific population matrix, the Lefkovitch matrix, to the northern anchovy Engraulis mordax and the Pacific sardine Sardinops sagax to determine which vital rates in the life history have the most effect on population growth. Three vital rates considered are the daily stage-specific instantaneous mortality rate, stage duration and daily age-specific fecundity per female. The models incorporate variability in growth rates among individuals and link simpler stage-based and more complicated individual-based modeling approaches. The elasticity of population growth rate for anchovy (percentage change from a $1 \%$ change of a vital rate) was greatest for mortality in yolk-sac larvae, fecundity of 2 yr old fish (111 to $135 \mathrm{~mm}$ ), and stage duration in late larvae (11 to $35 \mathrm{~mm})$. For sardine, elasticity was greatest for mortality in life stages of egg and yolk-sac larvae, fecundity of 5 and 6 yr old fish (211 to $250 \mathrm{~mm}$ ), and stage duration in the early larvae (5 to $10 \mathrm{~mm}$ ). When stage duration was variable, elasticity was $1 / 10$ as large as when stage duration was constant, indicating that sensitivity of populations to changes in vital rates is reduced by variation in growth rates. Population growth rates for both species increased with variance in individual growth rates. Thus, a population with individuals that grow at varying rates is more likely to increase. Our models indicate that growth rates are important determinants of population growth and recruitment and it is likely that growth and mortality rates are linked. We suggest, therefore, that inexpensive estimates of larval growth rates could be used to help forecast future recruitment.
\end{abstract}

KEY WORDS: Population matrix projection model S Sensitivity - Stage-specific vital rates - Pelagic fish - Stage duration

\section{INTRODUCTION}

Recruitment of juveniles is the key factor controlling population abundance of short-lived fish such as anchovies and sardines. Recruitment prediction, a subject of considerable practical significance, requires detailed knowledge of the factors influencing survival in the first months of life. These fish inhabit diverse and variable regions of the coastal ocean, and the processes controlling their recruitment are complex. Thus, we may expect regional differences, nonlinear relationships, and stochastic variability of parameters in the underlying models. Once plausible models are identified, missing or imprecise parameter estimates often hinder recruitment prediction. Existing assessment procedures, e.g. the egg production method (Lasker 1985) and fishery catch-at-age models

•E-mail: nlo@ucsd.edu
(Megrey 1989, Methot 1989, Deriso 1993), provide estimates of spawning biomass and vital rates for some life stages (Smith 1985, Butler et al. 1993). There are an increasing number of estimates of larval fish mortality (Beyer 1989, Pepin 1991) from laboratory and field studies (reviewed by Houde \& Zastrow 1993). The collection of vital rates for various life stages, although not contemporaneous, provides a basis for studying population changes (Crouse et al. 1987).

Determining the sensitivity of population growth to changes in vital rates of each life stage is a useful way to study the mechanisms underlying population growth and recruitment of marine fish (MacCall 1980). Smith (1985) advanced this idea using a life table approach, in which he determined the stage-specific vital rates which could cause a 5-fold change in recruitment of the northern anchovy Engraulis mordax. Smith et al. (1992) extended this work to the Pacific sardine 
Sardinops sagax using the Lefkovitch matrix, which is a generalization of the Leslie matrix (Lefkovitch 1965, Crouse et al. 1987, Caswell 1989). Smith et al. (1992) changed the value of each vital rate while holding others unchanged to achieve a $30 \%$ annual increase or decrease from a stationary population, a typical rate of population change during periods of sharp growth or decline. Barnes et al. (1992) demonstrated a $27 \%$ annual increase of Pacific sardine during 1983 to 1991 in the presence of a fishery. Butler et al. (1993) reviewed the literature, including recent estimates, and compared population growth for the minimum and maximum value for each parameter to identify critical life history stages for recruitment prediction.

In Smith et al. (1992) and Butler et al. (1993), the vital rates were first tuned to reach a stationary population ( $\lambda=1$ where $\lambda=N_{t} / N_{t-1}$ and $N_{t}$ is the population size at time $t$ ). These 2 studies assumed that fish grew at the same rate, so that the time spent in each stage was constant. Recent modeling work has shown, however, that changes in the variance as well as mean growth may affect fish survivorship (Pepin 1989, DeAngelis et al. 1993, Rice et al. 1993). Thus, variation in individual growth rates within stages may be important. In this paper, we relaxed the assumption of fixed stage duration and allowed the duration to vary because fish grow at different rates. We used a general formula to compute the sensitivity for each stage-specific vital rate and used a measure of elasticity which makes it easier to compare the sensitivity of the population to vital rate changes. In addition, we approximated $95 \%$ confidence intervals of the population growth index through simulations and investigated the impact of variance of duration within stages on population growth

\section{MATERIALS AND METHODS}

Model. The Lefkovitch matrix (A) describes the projection of a population from time $t$ to time $t+1$ in terms of the vital rates of each life stage:

$$
\mathrm{A} n_{t}=n_{i+1}
$$

where $n_{t}$ is a $q \times 1$ vector describing the stage distribution of population at time $t, q$ is the number of stages, and $t$ is measured in days.

$\mathbf{A}$ is the population projection matrix:

$\begin{array}{cccccc}P_{1} & F_{2} & . & & & F_{q} \\ G_{1} & P_{2} & 0 & & 0 & 0 \\ 0 & G_{2} & P_{3} & 0 & & 0 \\ & & & & & \\ 0 & 0 & 0 & & G_{q-1} & P_{q}\end{array}$

where $P_{l}$ is the probability of surviving and staying in Stage $i, G_{i}$ is the probability of surviving and growing into the next stage, and $F_{j}$ is the fertility per fish per day; $i=1, \ldots, q$. For a stable population, the dominant eigenvalue of matrix $\mathbf{A}, \lambda$, measures the population growth on the unit time basis. The corresponding eigenvector $(W)$ is the stable stage distribution because

and

$$
\mathbf{A} W=\lambda W
$$$$
\mathrm{A} n_{t}=\lambda n_{t}=n_{t+1} .
$$

The natural logarithm of $\lambda[\ln (\lambda)=r]$ is the intrinsic rate of population change.

In Eq. (1), each of the elements, $P_{n} G_{n}$ and $F_{n}$ depends on the probability of growing into the next stage, $\gamma_{1}$ (Appendix A). Various methods are available for estimating the growth probability which primarily depends on the duration within a stage (Caswell 1989). We assumed the duration $\left(d_{1}\right)$ follows a negative binomial distribution with parameters $\gamma_{i}$ (probability of successes) and $k$, (number of successes), because this distribution is flexible and is widely used in modeling the duration distribution (Blythe et al. 1984, Caswell 1989). The 2 parameters, $\gamma_{1}$ and $k_{1}$ of a negative binomial distribution are the growth probability and number of pseudostages within a stage. The pseudostages are imaginary stages which help to model the distribution of duration within stage. The duration is analogous to the number of trials taken to observe $k_{i}$ successes. Estimates of mean duration and the coefficient of variation $[\mathrm{CV}(d)=\mathrm{SD}(d) /$ mean $(d)]$ are then used to estimate the 2 parameters (Table 1). For details of description of matrix $\mathbf{A}$ and procedures of modeling growth rates, see Appendix A

For the anchovy, 9 life stages were defined: eggs, yolk-sac larvae, larvae $<10 \mathrm{~mm}$ in length, and larvae to adults grouped by $25 \mathrm{~mm}$ length intervals. The interval size of $25 \mathrm{~mm}$ was an arbitrary choice. The CVs of duration were available for 6 stages. The $\mathrm{CV}$ for anchovy eggs $(=0.10)$ was computed from the incubation time of eggs in laboratory rearing experiments (Lo 1983). CVs for 5 stages from 5 to $110 \mathrm{~mm}$ were computed from back-calculated growth rates from daily increments in otoliths of 94 juvenile anchovies born in March 1980 (Butler 1989) (Table 1). No CVs were available for the yolk-sac larval stage and the 2 adult stages, so values from adjacent stages were used: the $\mathrm{CV}$ of the early larvae $(5$ to $10 \mathrm{~mm}$ ) was applied to the yolk-sac stage, and the CV for the prerecruits was also applied to the adult stages.

For the sardine, 13 life stages were defined in the same way as for the anchovy. CVs for 7 stage durations from 5 to $110 \mathrm{~mm}$ were computed from back-calculated length-age data for 46 sardines with birth dates 
Table 1. Engraulis mordax and Sardinops sagax. Summary statistics for duration (days) in stages. Durations from early larvae to later stages for anchovies and sardines were back-calculated with assumed birth dates in March 1980 for anchovies, February and June 1984 for sardines. $y$ and $k$ are parameter estimates for negative binomial distribution, computed from sample mean and SD. Lv: larvae; Jv: juvenile; Prerec: prerecrujts; Adt: adult. Numbers in parentheses are estimates from the adjacent stage

The CV of duration for anchovy eggs was also used for sardine eggs

\begin{tabular}{|c|c|c|c|c|c|c|c|c|c|}
\hline \multicolumn{3}{|c|}{ Length interval $(\mathrm{mm})$ : } & 5 to 10 & 11 to 35 & 36 to 60 & 61 to 85 & 86 to 110 & 111 to 135 & 136 to 160 \\
\hline \multicolumn{5}{|l|}{ Anchovy } & Early Jv & Late Jv & Prerec & Early Adt & Late Adt \\
\hline N & 69 & - & 92 & 94 & 94 & 94 & 45 & 0 & 0 \\
\hline Mean & 2.69 & - & 18.23 & 40.81 & 65.74 & 93.13 & 158.10 & - & - \\
\hline SD & 0.26 & - & 4.74 & 9.04 & 10.13 & 31.73 & 64.31 & - & - \\
\hline $\mathrm{CV}$ & 0.095 & $(0.26)$ & 0.26 & 0.22 & 0.15 & 0.34 & 0.41 & $(0.41)$ & $0.41)$ \\
\hline$\gamma$ & 0.98 & - & 0.48 & 0.33 & 0.39 & 0.08 & 0.04 & - & - \\
\hline k & 2.63 & - & 8.17 & 13.59 & 25.67 & 7.88 & 5.82 & - & - \\
\hline \multicolumn{10}{|l|}{ Sardine } \\
\hline Life stage: & Eggs & Ys Lv & Early Lv & Late Lv & Early Jv & JV I & JV II & $J_{V}$ III & JV IV \\
\hline$N$ & - & - & 42 & 46 & 46 & 45 & 38 & 25 & 2 \\
\hline Mean & - & - & 16.13 & 59.13 & 29.07 & 31.29 & 53.03 & 71.46 & 90.11 \\
\hline $\mathrm{SD}$ & - & - & 4.38 & 10.13 & 5.55 & 6.98 & 17.70 & 13.85 & 22.23 \\
\hline $\mathrm{CV}$ & $(0.095)$ & $(0.27)$ & 0.27 & 0.17 & 0.19 & 0.22 & 0.33 & 0.19 & 0.25 \\
\hline$\gamma$ & - & - & 0.45 & 0.37 & 0.49 & 0.39 & 0.14 & 0.27 & 0.15 \\
\hline$k$ & - & - & 7.41 & 21.62 & 14.10 & 12.24 & 7.68 & 19.40 & 13.89 \\
\hline
\end{tabular}

in February and June 1984 (Table 1) (Butler 1989). The CVs of eggs, yolk-sac larvae, and 4 stages $>160 \mathrm{~mm}$ were not available. CV for anchovy eggs was used for sardine eggs as anchovy and sardine egg development is similar (Zweifel \& Lasker 1976). The CV of early larvae $(5$ to $10 \mathrm{~mm}$ ) was applied to the yolk-sac larvae. The CV for the juveniles (136 to $160 \mathrm{~mm}$ ) was also applied to the older stages.

Data analyses. In matrix A (Eq. 1), $P_{j}$ and $G_{i}$ are nonlinear functions of the daily instantaneous mortality rate $\left(\operatorname{IMR}, z_{1}\right)$ and duration $\left(d_{1}\right)$, and the fertility $\left(F_{1}\right)$ naturally also depends on daily age-specific fecundity $\left(f_{j}\right)$ for age $j$ (Appendix A). These vital rates $\left(z_{i}, d_{i}, f_{j}\right)$ are the primary input parameters. Based on these available estimates for vital rates, one can derive each element in matrix A (Appendix A; Eqs. A1 to A6). Although the vital rates are the central focus of the sensitivity analyses in this study, we also included $P_{i}, G_{1}$ and $F_{1}$ for comparative purposes because they are commonly used in other studies (Crouse et al. 1987, Caswell 1989).

Estimates of daily IMR $(z)$, duration (d) for each stage, and the daily age-specific fecundity $\left(f_{j}\right)$ of northern anchovies and Pacific sardines were obtained from the literature (Smith 1985, Lo 1986, Butler 1987, Butler et al. 1993) (Tables 2 to 5). The age-specific fecundity rates were later converted to length-specific fecundity rates (see Appendix A). For a detailed description of the stage-specific vital rates of anchovies and Pacific sardines, see Butler et al. (1993). Butler selected $z$ values for the early-juvenile stage of the anchovy and juvenile- 1 stage of the sardine to achieve a stationary population $(\lambda=1)$. In contrast, we obtained regression estimates of $z$ for both stages in anchovy and sardine from a Pareto function of $z$ regressed on age (cumulated duration) (Lo 1986; Table 2). Vital rates $z_{11} d_{j}$ and $f_{j}$ were applied to each pseudostage within Stage i, i.e. $P_{i m}=P_{i k} G_{i m}=G_{i k}$ for $m \neq k$ where $m$ and $k$ refer to pseudostages within Stage $i$. This relationship is not true for fertility $\left(F_{i}\right)$, so an average fertility over the pseudostages was computed within a stage.

Elasticity analyses. The change of the population growth, $\lambda$, due to the change of any one vital rate $(x)$ within a stage can be measured by the sensitivity index $\left(S_{x}\right)$ :

$$
\begin{aligned}
S_{x} & =\partial \lambda / \partial x \\
& =\sum_{i} \sum_{j} \frac{\partial \lambda}{\partial a_{i j}} \frac{\partial a_{i j}}{\partial x} \\
& =\sum_{i} \sum_{j} S_{i j} \frac{\partial a_{i j}}{\partial x}
\end{aligned}
$$

The sensitivity index $\left(S_{i j}\right)$ for each element of matrix $\mathrm{A}$ $\left(a_{i j}\right)$ was computed:

$$
S_{i j}=\frac{\partial \lambda}{\partial a_{i j}}=\frac{v_{i} w_{j}}{\sum\left(w_{i} v_{l}\right)}
$$


Table 2. Engraulis mordax. Daily instantaneous mortality rate (IMR) and stage duration for anchovies. SD is computed from CV, which measures among-year variation. Lv: larvae; Jv: juvenile; Adt: adult

\begin{tabular}{|c|c|c|c|c|c|c|c|c|}
\hline \multirow[t]{2}{*}{ Stage } & \multirow[t]{2}{*}{ Name } & \multicolumn{3}{|c|}{- IMR } & \multicolumn{3}{|c|}{ —_ Duration (days) } & \multirow[t]{2}{*}{ Length (mm } \\
\hline & & Estimates & $\mathrm{CV}$ & $\mathrm{SD}$ & Estumates $^{d}$ & $\mathrm{CV}$ & $\mathrm{SD}$ & \\
\hline 1 & Egg & 0.2310 & 0.36 & 0.0832 & 2.90 & 0.22 & 0.63 & \\
\hline 2 & Yolk-sac & 0.3660 & 0.15 & 0.0560 & 3.60 & 0.17 & 0.62 & $\mathrm{H}^{\mathrm{b}}-4$ \\
\hline 3 & Early Lv & 0.2860 & 0.05 & 0.0147 & 12.00 & 0.31 & 3.75 & $5-$ \\
\hline 4 & Late Lv & 0.0719 & 0.05 & 0.0038 & 45.00 & 0.20 & 9.00 & $11-$ \\
\hline 5 & Early Jv & $0.0107^{c}$ & 0.05 & 0.0006 & 62.00 & 0.22 & 13.75 & $36-$ \\
\hline 6 & Late Jv & 0.0044 & 0.05 & 0.0002 & 80.00 & 0.24 & 19.50 & $61-$ \\
\hline 7 & Prerecruit & 0.0031 & 0.05 & 0.0001 & 287.00 & 0.38 & 108.00 & $86-$ \\
\hline 8 & Early Adt & 0.0021 & 0.18 & 0.0004 & 1000.00 & 0.13 & 125.00 & $111-$ \\
\hline 9 & Late Adt & 0.0021 & 0.18 & 0.0004 & 1250.00 & 0.10 & 125.00 & $136-160$ \\
\hline
\end{tabular}

where $w_{1}$ is the ith element of the right eigenvector and $V$, is the $j$ th element of the left eigenvector $(\mathbf{A} W=\lambda W$, $V^{\prime} \mathbf{A}=\lambda V^{\prime}$ ) (Caswell 1.989). For example, $S_{12}$ is the sensitivity index for $G_{1}$ (Eq. 1). Formulas for the sensitivity index of vital rates are given in Appendix B.

When vital rates differ in magnitude, it is useful to examine the percentage change of population growth due to a $1 \%$ change of a vital rate. The elasticity $\left(e_{x}\right)$ can be used to compute the daily population growth when vital rates change. The proportional sensitivity or elasticity, $e_{x}$ is defined:

$$
e_{x}=\frac{\partial \lambda / \lambda}{\partial x / x}
$$

For example, if $e_{x}$ is -0.005 , then the population decreases by $0.005 \%$ for a $1 \%$ increase of vital rate $x$. The elasticities are computed from an expanded matrix $\mathbf{A}_{\text {, }}$ the dimensions of which are $n \times n$, where $n=\sum k_{i}$ and $k_{1}$ is the number of pseudostages within Stage $i$.

Table 3. Engraulis mordax. Batch fecundity/1000 by age for northern anchovy population in which $90 \%$ of females mature in the first year

\begin{tabular}{|c|c|c|c|c|c|}
\hline $\begin{array}{l}\text { Age } \\
(\mathrm{yr})\end{array}$ & $\begin{array}{c}\text { Fish } \\
\text { weight }(g)\end{array}$ & $\begin{array}{c}\text { Batches } \\
\mathrm{yr}^{-1}\end{array}$ & $\begin{array}{c}\text { Eggs } \\
\text { batch }^{-1}\end{array}$ & $\begin{array}{l}\text { Eggs female } \\
\text { Estimates }\end{array}$ & $\begin{array}{r}\mathrm{d}^{-1}\left(f_{j}\right) \\
\mathrm{SD}^{\mathrm{a}}\end{array}$ \\
\hline 1 & 8.7 & 5.3 & 4.2378 & 61.5352 & 1.85 \\
\hline 2 & 14.6 & 11.9 & 7.8604 & 256.2706 & 7.69 \\
\hline 3 & 18.3 & 19.2 & 10.1322 & 532.9815 & 15.99 \\
\hline 4 & 21.2 & 23.5 & 11.9128 & 766.9885 & 23.01 \\
\hline 5 & 24.5 & 23.5 & 13.9390 & 897.4425 & 26.92 \\
\hline 6 & 24.2 & 23.5 & 13.9390 & 897.4425 & 26.92 \\
\hline 7 & 24.5 & 23.5 & 13.9390 & 897.4425 & 26.92 \\
\hline
\end{tabular}

Variability of estimate of daily population growth rate $\lambda$. Once matrix $A$ is determined, $\lambda$ can be computed by using mathematical packages (e.g. MATLAB) or by continuous multiplication of matrix A with an arbitrary initial stage vector $\left(n_{0}\right): \mathbf{A}^{t} n_{0}=$ $n_{t ;} \lambda=n_{l} / n_{t-1}$ for large $t$. We used the continuous multiplication procedure. The elements of matrix A $\left(a_{i j}\right)$ are functions of vital rates, which are estimated with errors, thus the estimate of $\lambda$ is also subject to error.

Monte Carlo simulations were used to estimate the variance of $\hat{\lambda}$ and as \% confidence interval (CI) of $\lambda$. In this simulation, IMR, $d$ within each stage, and the daily $f_{j}$ were drawn independently from normal distribution with means equal to best estimates (Butler et al. 1993; Tables 2 to 5). The SDs of vital rates of both species were estimated from range values reported in Butler et al. (1993) as $\operatorname{SD}(x)=[\max (x)-\min (x)] / 4$, except for the IMR of anchovy eggs and daily fecundity rates. The $\mathrm{CV}$ for anchovy eggs is 0.36 (Jacobson \& Lo 1992); for fecundity of anchovy, 0.03 (Hunter et al. 1985). The CV for fecundity was also applied to the sardine (Tables 3 \& 5).

In the simulation, vital rates were checked to be sure they were biologically reasonable (no negative values were allowed). For each set of simulated input parameters, Eqs. A1 to A6 (Appendix A) were used to compute elements in matrix A. $\hat{\lambda}$ was calculated by continuous multiplication of matrix A 3000 times. Mean and SD were obtained from 1000 simulations. The $95 \% \mathrm{CI}$ for $\lambda$ was also obtained. 
Table 4. Sardinops sagax. Daily instantaneous mortality rates (IMR) and stage duration for Pacific sardines. SD is computed from CV which measures among-year variation. Lv: larvae; Jv: juvenile; Adt: adult

\begin{tabular}{|c|c|c|c|c|c|c|c|c|}
\hline \multirow[t]{2}{*}{ Stage } & \multirow[t]{2}{*}{ Name } & \multicolumn{3}{|c|}{$\longrightarrow$ IMR } & \multicolumn{3}{|c|}{$\longrightarrow$ Duration (days) } & \multirow[t]{2}{*}{ Length $(\mathrm{mm})$} \\
\hline & & Estimates & $\mathrm{CV}$ & $\mathrm{SD}$ & Estimates ${ }^{\mathrm{d}}$ & $\mathrm{CV}$ & $\mathrm{SD}$ & \\
\hline 1 & Egg & 0.7200 & 0.63 & 0.4525 & 2.5 & 0.25 & 0.63 & - \\
\hline 2 & Yolk-sac & 0.6690 & 0.22 & 0.1447 & 3.1 & 0.20 & 0.63 & $H^{b}-4$ \\
\hline 3 & Early Lv & 0.2417 & 0.22 & 0.0520 & 11.0 & 0.36 & 4.00 & $5-$ \\
\hline 4 & Late Lv & 0.0964 & 0.21 & 0.0205 & 35.0 & 0.21 & 7.50 & $11-$ \\
\hline 5 & Early JV & 0.0560 & 0.23 & 0.0130 & 25.0 & 0.23 & 5.75 & $36-$ \\
\hline 6 & Jv I & $0.0146^{c}$ & 0.21 & 0.0031 & 50.0 & 0.25 & 12.50 & $61-$ \\
\hline 7 & JV II & 0.0040 & 0.22 & 0.0009 & 110.0 & 0.15 & 16.50 & $86-$ \\
\hline 8 & JV III & 0.0028 & 0.21 & 0.0006 & 146.0 & 0.14 & 20.00 & $111-$ \\
\hline 9 & JV IV & 0.0022 & 0.23 & 0.0005 & 170.0 & 0.16 & 27.50 & $136-$ \\
\hline 10 & Prerecruit & 0.0011 & 0.20 & 0.0002 & 175.0 & 0.16 & 27.50 & $161-$ \\
\hline 11 & Early Adt & 0.0011 & 0.20 & 0.0002 & 381.0 & 0.25 & 95.00 & $186-$ \\
\hline 12 & Adult & 0.0011 & 0.36 & 0.0004 & 663.0 & 0.20 & 130.00 & $211-$ \\
\hline 13 & Late Adt & 0.0011 & 0.36 & 0.0004 & 2773.0 & 0.14 & 391.25 & $236-250$ \\
\hline \multicolumn{9}{|c|}{$\begin{array}{l}\text { dValues of this column were derived from growth curves (Butler et al. 1993) and may differ from Table } 1 \\
\text { b Hatching } \\
\text { 'Regression estimate from } \ln (z)=2.03-1.29 \ln (\text { age }+1 \text { ) based on data from Stages } 1 \text { to } 10 \text { where age is the cumulative } \\
\text { duration }\end{array}$} \\
\hline
\end{tabular}

\section{RESULTS}

\section{Northern anchovy}

The projection matrix A with time step equal to $1 \mathrm{~d}$ was constructed (Table 6). Each entry of matrix A was used for all pseudostages within a stage. The dimensions of the expanded matrix $\mathbf{A}$ are $79 \times 79$. The dominant eigenvalue of the expanded matrix $\mathbf{A}$ is 1.00105 The intrinsic daily population growth rate is

Table 5. Sardinops sagax. Batch fecundity/1000 by age for Pacific sardine population in which $50 \%$ of females mature at age 2

\begin{tabular}{|c|c|c|c|c|c|}
\hline \multirow{2}{*}{$\begin{array}{l}\text { Age } \\
\text { (yr) }\end{array}$} & \multirow{2}{*}{$\begin{array}{c}\text { Fish } \\
\text { weight }(\mathrm{g})\end{array}$} & \multirow{2}{*}{$\begin{array}{c}\text { Batches } \\
\mathrm{yr}^{-1}\end{array}$} & \multirow{2}{*}{$\begin{array}{c}\text { Eggs } \\
\text { batch-1 }\end{array}$} & \multicolumn{2}{|c|}{ Eggs female ${ }^{-1} \mathrm{~d}^{-1}\left(f_{j}\right)$} \\
\hline & & & & Estimates & $\mathrm{SD}^{\mathrm{a}}$ \\
\hline 1 & 52.7 & 0 & 0 & 0 & 0 \\
\hline 2 & 93.0 & 6 & 24.459 & 402.066 & 12.06 \\
\hline 3 & 123.0 & 12 & 32.349 & 1063.529 & 31.91 \\
\hline 4 & 152.0 & 15 & 39.976 & 1642.849 & 49.29 \\
\hline 5 & 170.0 & 19 & 44.710 & 2327.370 & 69.82 \\
\hline 6 & 193.0 & 23 & 50.759 & 3198.512 & 95.96 \\
\hline 7 & 202.0 & 28 & 53.126 & 4075.419 & 122.26 \\
\hline 8 & 205.0 & 30 & 53.915 & 4431.370 & 132.94 \\
\hline 9 & 205.0 & 35 & 53.915 & 5169.932 & 155.10 \\
\hline 10 & 205.0 & 40 & 53.915 & 5908.493 & 177.25 \\
\hline 11 & 205.0 & 40 & 53.915 & 5908.493 & 177.25 \\
\hline 12 & 205.0 & 40 & 53.915 & 5908.493 & 177.25 \\
\hline 13 & 205.0 & 40 & 53.915 & 5908.493 & 177.25 \\
\hline
\end{tabular}

$\ln (1.00105)=0.00105$ (Table 7). A crude estimate of the annual population growth rate is $1.46\left(1.00105^{365}\right)$.

The elasticity analysis indicated that a relative change in the IMR of yolk-sac anchovy larvae results in the largest percentage change in population growth. For fecundity, the population is most sensitive to the $1 \%$ change in daily fecundity rate of 2 yr old fish (111 to $135 \mathrm{~mm}$; Stage 8). For the duration of stages, the population growth is mostly sensitive to a percentage change in late larvae (Stage 4 ; Fig. 1).

Elasticity estimates for 3 vital rates can be used to compute the percentage change of population growth for $x \%$ change of 1 particular vital rate. For example, if the IMR of yolk-sac larvae is reduced by $10 \%$, i.e. from 0.37 to 0.33 (Table 2), then the daily population growth will be increased by $0.0052 \%\left(e_{x} \times\right.$ $10 \%$; Table 7 ). If the duration of the late larval stage is increased by $10 \%$ from 45 to $49 \mathrm{~d}$, the population would be decreased by $0.00212 \%$ daily. If the daily fecundity of 2 yr old females is increased by $5 \%$ from 256 to 269 , the population would be increased by $0.00428 \%\left(e_{x} \times 5 \%\right)$ daily.

From the 1000 simulation runs, we obtained the mean and SD for $\hat{\lambda}$ as 1.0016 and 0.0011 . The $95 \%$ CI for $\lambda$ is 0.9992 to 1.0054 , and includes $\lambda=1$. Thus, the null hypothesis of a stationary population is not rejected. 
Table 6. Engraulis mordax. The projection matrix (Eq. 1) of northern anchovy with variable duration and number of pseudostages within each stage. $\lambda=1.00105 . k$ : number of pseudostages (Eq. A4). For stage definition, see Table 2

\begin{tabular}{|c|c|c|c|c|c|c|c|c|c|}
\hline Stage & 1 & 2 & 3 & 4 & 5 & 6 & 7 & 8 & 9 \\
\hline 1 & $0.224 \times 10^{-1}$ & 0.0 & 0.0 & 0.0 & 0.0 & 0.0 & $0.928 \times 10^{1}$ & $0.978 \times 10^{2}$ & $0.351 \times 10^{3}$ \\
\hline 2 & 0.771 & 0.136 & 0.0 & 0.0 & 0.0 & 0.0 & 0.0 & 0.0 & 0.0 \\
\hline 3 & 0.0 & 0.558 & 0.336 & 0.0 & 0.0 & 0.0 & 0.0 & 0.0 & 0.0 \\
\hline 4 & 0.0 & 0.0 & 0.415 & 0.638 & 0.0 & 0.0 & 0.0 & 0.0 & 0.0 \\
\hline 5 & 0.0 & 0.0 & 0.0 & 0.293 & 0.576 & 0.0 & 0.0 & 0.0 & 0.0 \\
\hline 6 & 0.0 & 0.0 & 0.0 & 0.0 & 0.413 & 0.898 & 0.0 & 0.0 & 0.0 \\
\hline 7 & 0.0 & 0.0 & 0.0 & 0.0 & 0.0 & $0.972 \times 10^{-1}$ & 0.977 & 0.0 & 0.0 \\
\hline 8 & 0.0 & 0.0 & 0.0 & 0.0 & 0.0 & 0.0 & $0.202 \times 10^{-1}$ & 0.992 & 0.0 \\
\hline 9 & 0.0 & 0.0 & 0.0 & 0.0 & 0.0 & 0.0 & 0.0 & $0.590 \times 10^{-2}$ & 0.993 \\
\hline$k$ & 3 & 3 & 7 & 14 & 26 & 8 & 6 & 6 & 6 \\
\hline \multicolumn{10}{|c|}{ Total number of pseudostages $=79$} \\
\hline \multicolumn{10}{|c|}{$\begin{array}{l}\text { The expanded projection matrix consists of the first } 3 \text { 'pseudostages' with } P_{1}=0.0224 \text { and } G_{1}=0.771 \text { and the next } 3 \text { pseudo } \\
\text { stages with } P_{1}=0.136 \text { and } G_{j}=0.558 \text {, etc. Fertilities for the last } 3 \text { stages are the averages of fertilities for the pseudostages } \\
\text { within stages }\end{array}$} \\
\hline
\end{tabular}

\section{Pacific sardine}

The projection matrix A with time steps equal to $1 \mathrm{~d}$ was constructed (Table 8). The dimensions of the expanded matrix A are $167 \times 167$ and the dominant eigenvalue is 1.00014 . The intrinsic daily population growth rate is $\ln (1.00014)=0.00014$ (Table 7$)$. A crude estimate of the annual population growth rate would be $1.052\left(1.00014^{365}\right)$.

Table 7 . Engraulis mordax and Sardinops sagax. Estimates of daily population growth rate $(\lambda)$, standard errors in parentheses and the most elastic stages of anchovy and sardine for 2 models: fixed duration and variable duration within stage. IMR: instantaneous mortality rate; YL: yolk-sac larvae; EL: early larvae; LL: late larvae; CI: confidence interval

\begin{tabular}{|c|c|c|}
\hline & $\begin{array}{l}\text { Fixed duration } \\
\text { within stage }\end{array}$ & $\begin{array}{c}\text { Variable duration } \\
\text { within stage }\end{array}$ \\
\hline \multicolumn{3}{|l|}{ Anchovy } \\
\hline \multicolumn{3}{|l|}{$\lambda$} \\
\hline Direct computation & 1.000479 & 1.00105 \\
\hline Simulation & & $1.0016(0.0011)$ \\
\hline $95 \% \mathrm{Cl}$ & & $0.9992-1.0054$ \\
\hline \multicolumn{3}{|l|}{ Elasticity $\left(e_{x}\right)$} \\
\hline IMR & EL: -0.0048 & YL: -0.00052 \\
\hline Duration & EL: -0.0048 & LL: -0.000212 \\
\hline Fecundity & Age 2: 0.00043 & Age 2: 0.000857 \\
\hline \multicolumn{3}{|l|}{ Sardine } \\
\hline \multicolumn{3}{|l|}{$\lambda$} \\
\hline Direct computation & 0.99983 & 1.00014 \\
\hline Simulation & & $1.0003(0.0011)$ \\
\hline $95 \% \mathrm{Cl}$ & & $0.9987-1.002$ \\
\hline \multicolumn{3}{|l|}{ Elasticity $\left(e_{x}\right)$} \\
\hline IMR & LL: -0.00160 & Egg, YL: -0.0004 \\
\hline Duration. & LL: -0.00161 & EL: -0.00007 \\
\hline Fecundity & Age 5: 0.0008 & Age 5: 0.0002 \\
\hline
\end{tabular}

Similar to northern anchovies, the elasticity analysis for sardines indicated that the largest percentage change in population growth came from a relative change in the IMR of egg and yolk-sac sardine larvae, followed by larval stages (Table 7, Fig. 2). For $f_{j}$ per female, population growth is most sensitive to the percent-age change in 5 yr old females $(211$ to $235 \mathrm{~mm}$; Stage 12). For stage duration, the population growth is most sensitive to a relative change in early larvae (Stage 3).

A $10 \%$ increase of the daily IMR for the yolk-sac larvae from 0.67 to 0.74 (Table 4) would result in a decrease of $0.004 \%$ for the population. Likewise, with a $10 \%$ decrease of duration for the early larvae from 11 to $10 \mathrm{~d}$, the population would be increased by $0.0007 \%$ daily. If the daily fecundity of $5 \mathrm{yr}$ old females is increased by $20 \%$ from 2327 to 2792 , the population would be increased by $0.004 \%$ daily (Table 7).

From the simulation, we obtained mean and SD of $\bar{\lambda}$ as 1.0003 and 0.0011 . The $95 \% \mathrm{CI}$ for $\lambda$ is 0.9987 to 1.0028 . From the $95 \% \mathrm{CI}$ of $\lambda$, we cannot ascertain the direction of population growth of sardines.

\section{Elasticity of entries of matrix $\mathrm{A}\left(P_{i}, G_{i}\right.$ and $\left.F_{j}\right)$}

For both anchovies and sardines, the elasticity of population growth to the probability of survival and staying in the stage $\left(P_{i}\right)$ increases with stages until the last stage. Population size apparently is more sensitive to $P_{1}$ than to the probability of survival and growing into the next stage, $G_{11}$ and fertility, $F_{i}$ (Figs. $3 \& 4$ ). 


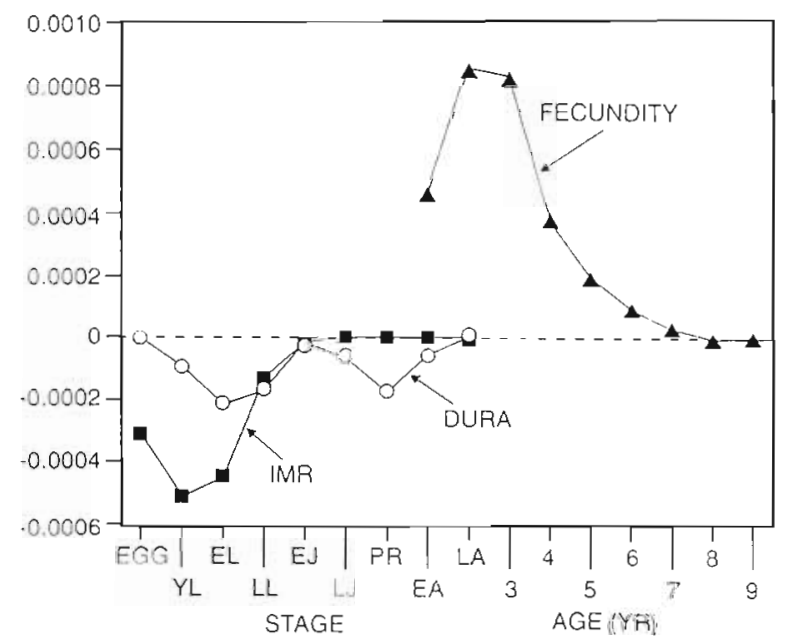

Fig. 1. Engraulis mordax. Elasticity of instantaneous mortality rate (IMR), duration (DURA) within each stage and daily agespecific fecundity for northern anchovy. YL: yolk-sac larvae EL: early larvae (4 to $10 \mathrm{~mm}$ ); LL: late larvae (11 to $35 \mathrm{~mm}$ ): EJ early juvenile ( 36 to $60 \mathrm{~mm}$ ); LJ: late juvenile $(61$ to $85 \mathrm{~mm}$ ) PR: prerecruits (86 to $110 \mathrm{~mm}$ ): EA: early adult (111 to $135 \mathrm{~mm}$ ); LA: late adult (136 to $160 \mathrm{~mm}$ )

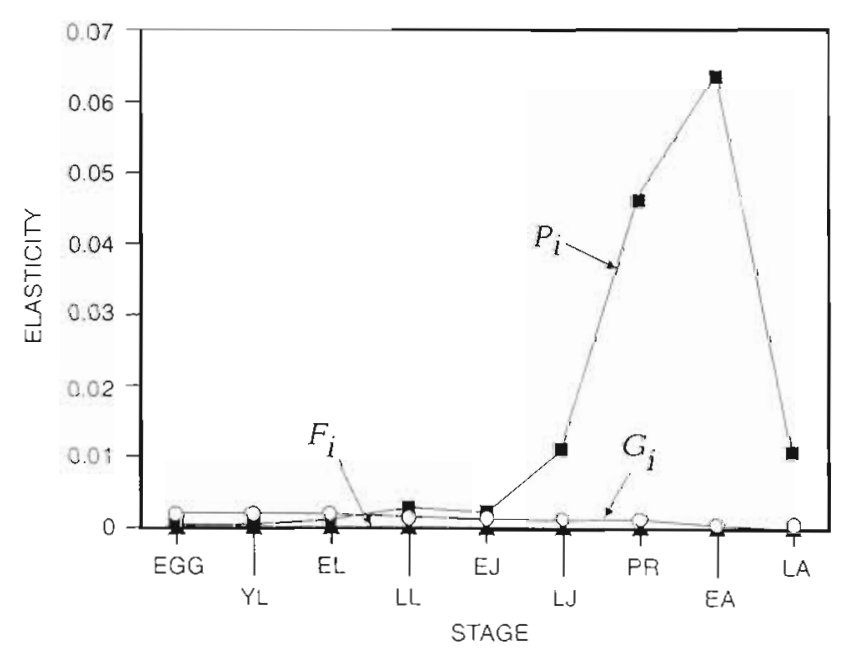

Fig. 3. Engraulis mordax. Elasticity of $P_{1}, G_{1}$ and $F_{k}$ elements of matrix $\mathbf{A}$ (Eq. 1) within each stage for northern anchovy YL: yolk-sac larvae; EL: early larvae (5 to $10 \mathrm{~mm}$ ); LL: Iate larvae (11 to $35 \mathrm{~mm}$ ); EJ: early juvenile (36 to $60 \mathrm{~mm}$ ); LJ: late juvenile (61 to $85 \mathrm{~mm}$ ): PR: prerecruits ( 86 to $110 \mathrm{~mm}$ ); EA: early adult (111 to $135 \mathrm{~mm}$ ); LA: late adult (136 to $160 \mathrm{~mm}$ )

\section{Relationship between variations of stage duration and $\lambda$}

In order to see how the variability of stage duration affects the rate of population growth, we considered 8 cases. In each case, all the initial CV values (Table 1) were multiplied by a constant, $c$, between 0 and 3.0 .

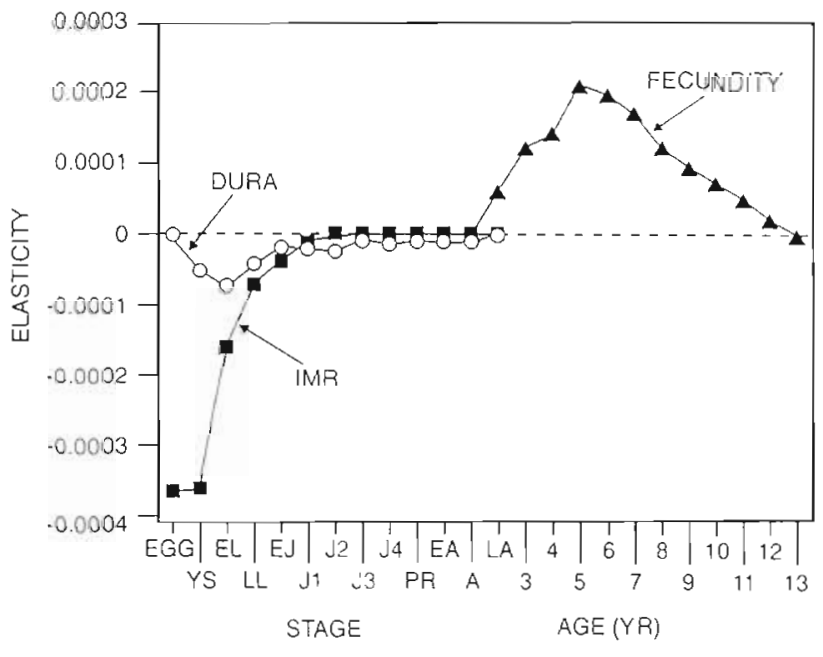

Fig. 2. Sardinops sagax. Elasticity of instantaneous mortality rate (IMR), duration (DURA) within each stage and daily agespecific fecundity for Pacific sardine. YL: yolk-sac larvae; EL: early larvae (5 to $10 \mathrm{~mm})$; LL: late larvae $(11$ to $35 \mathrm{~mm}$ ); EJ: early juvenile ( 36 to $60 \mathrm{~mm}$ ); $\mathrm{J} 1$. juvenile ( 61 to $85 \mathrm{~mm}$ ); $\mathrm{J} 2$ : juvenile ( 86 to $110 \mathrm{~mm}$ ); J3: juvenile (111 to $135 \mathrm{~mm}$ ); J4: juvenile (136 to $160 \mathrm{~mm}$ ); PR: prerecruits (161 to $185 \mathrm{~mm}$ ); EA early adult (186 to $210 \mathrm{~mm}$ ); A: adult (211 to $235 \mathrm{~mm}$ ); LA: late adult ( 236 to $250 \mathrm{~mm}$ )

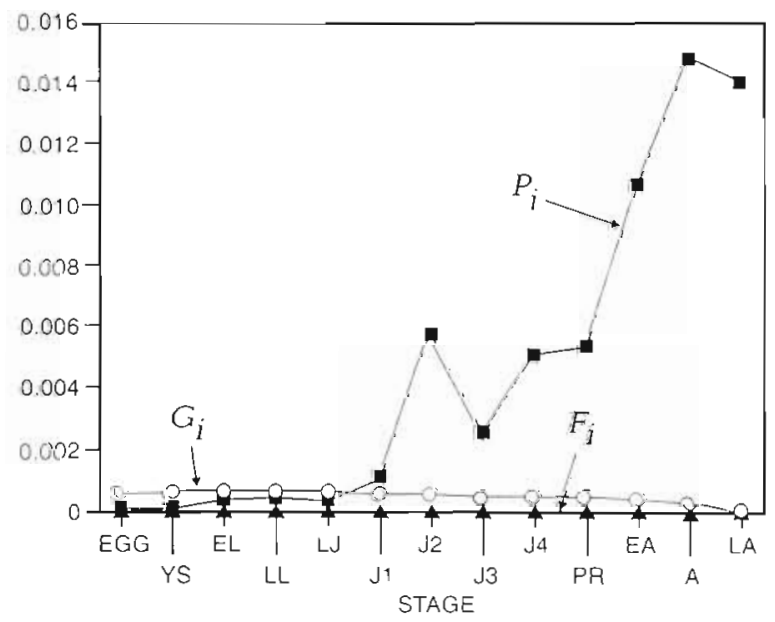

Fig. 4. Sardinops sagax. Elasticity of $P_{1}, G_{1}$ and $F_{1}$, elements of matrix A (Eq. 1) within each stage for Pacific sardine. YL: yolk-sac larvae; EL: early larvae ( 5 to $10 \mathrm{~mm}$ ); LL: late larvae (11 to $35 \mathrm{~mm}$ ); EJ: early juvenile ( 36 to $60 \mathrm{~mm}$ ); J1: juvenile (61 to $85 \mathrm{~mm}$ ); J2: juvenile ( 86 to $110 \mathrm{~mm}$ ); J3: juvenile (110 to $135 \mathrm{~mm}$ ); J4: juvenile (135 to $160 \mathrm{~mm}$ ); PR: prerecruits (161 to $185 \mathrm{~mm}$ ); EA: early adult (186 to $210 \mathrm{~mm}$ ); A: adult (211 to $235 \mathrm{~mm}$ ); LA: late adult ( 236 to $250 \mathrm{~mm}$ )

For example, when $c=0$, the duration within a stage does not vary. For $c=2$, this set of $C V$ is twice those $C V$ values given in Table 1 . We then computed $1 \lambda$ for each case. For both species, $\lambda$ increases with the constant (Fig. 5). Thus, a population with variable growth among individuals is more likely to increase in the long run, if everything is equal. These results are consistent 


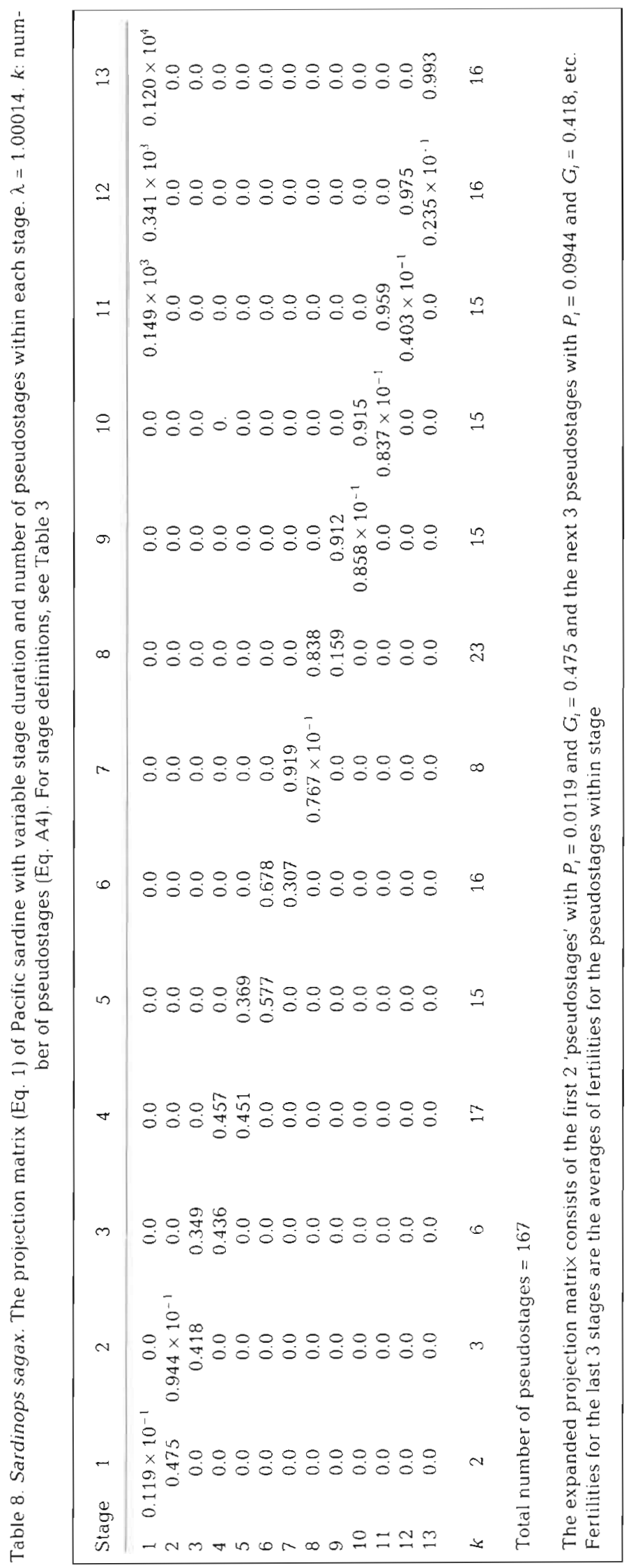

with the findings by Caswell (1989). Such a population does not readily react to the change of vital rates because of low elasticities (Table 7 ).

\section{DISCUSSION}

Our model incorporated the variation of somatic growth within stage (variable growth). We believe that this is more realistic than models assuming fixed stage duration (fixed growth). If the variances of somatic duration are unknown, fixed stage durations may have to be assumed although the results might be biased. For comparison purposes, we computed the population growth $(\lambda)$ and elasticity of vital rates for both species using fixed growth (Appendices A \& B). Our results for anchovies and sardines show that the $\lambda$ from models with variable duration was always higher than the $\lambda$ from models with fixed duration (Table 7 ). These results indicated that variation in growth rates of individuals enhanced the population growth, primarily due to sizedependent mortality (Tables $2 \& 4$ ). While the mathematical consequences of growth variability within each stage are clear, it will also be necessary to confirm the importance of these phenomena by field measurements. Pepin (1989) reported that mean and variance of growth rates of 1 cohort affect the survival rates of the population. Rice et al. (1993) found that high variation in larval growth leads to increased cohort survival after $60 \mathrm{~d}$, when the predation is sizedependent.

Population growth in our models for anchovies and sardines with variable duration is more sensitive to the percentage change of IMR and fecundity than to the percentage change in stage duration. With fixed duration, population growth is equally sensitive to the percentage change of mortality (IMR) and growth (duration) and not so sensitive to fecundity (Table 7). Elasticity values for IMR and duration from fixed growth are nearly 10 times that from variable growth. This difference implies that when the variance in the growth rates of individuals increases, the sensitivity of the population to changes in those rates decreases. The most elastic stages for both IMR and duration may differ depending on models used, yet the most elastic stages are from eggs to late larvae. Butler (1989) found that population growth of sardines was correlated with mortality of larvae, which is consistent with this study.

The population growth is a function of mean and variance of stage-specific vital rates, as 


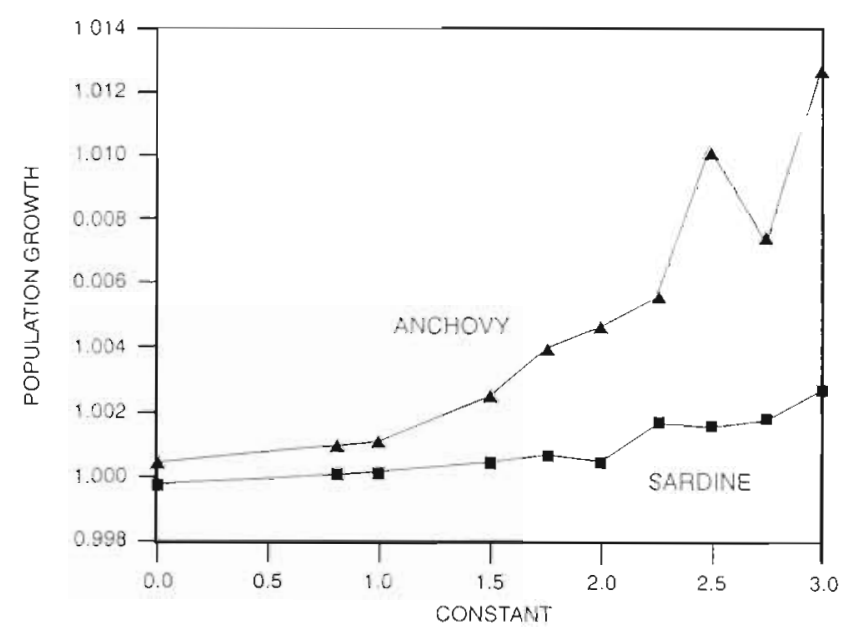

Fig. 5. Engraulis mordax and Sardinops sagax. Relationship between the population growth rate $(\lambda)$ and the constant used to multiply the coefficient of variation (CV) of stage duration for northern anchovy and Pacific sardine (Table 1). For example, when constant $=0.5$, the $\mathrm{CV}$ values for anchovy are 0.5 times the CV values of stage duration (Table 1): e.g. CV of stage duration is $0.0475(=0.5 \times 0.095)$ for anchovy eggs, 0.13 $(=0.5 \times 0.26)$ for yolk-sac larvae, 0.21 for prerecruits

demonstrated by the relationship between population growth and the constant used to multiply the $\mathrm{CV}$ of stage duration (Fig. 5). For northern anchovies and Pacific sardines, the most sensitive stages are early life stages whose vital rates have reasonable estimates. However, as for most fish populations, precise estimates of CVs for stage duration are not available. It would be useful to investigate the robustness and bias of population growth estimates from matrix models introduced by using crude estimates of both mean and CV of vital rates.

The most elastic stages for both species are similar: for the IMR, they are egg and yolk-sac larval stages, and for stage duration, they are early and late larval stages (Figs, 1 \& 2). The correspondence may be due to biological similarities between anchovies and sardines, and, perhaps, a general pattern in short-lived pelagic fish. Alternatively, it may result from use of identical parameter values in our models for both species, e.g. CV of egg duration. Maximum elasticities were greater for anchovies than for sardines. Thus, our models project that anchovy populations would change size more quickly than sardine populations, in response to proportional changes in a vital rate (Table 7).

Results from our models indicate that growth rates of early life history stages are important determinants of recruitment and population growth. It may be possible, therefore, to provide fishery managers with useful indicators of future recruitment based on larval growth rate data (Huppert et al. 1980). Pepin (1990) found that short-term variability in recruitment was associated with fluctuation in plankton abundance, indicating that growth rates may be an important factor in determining year-class strength. These fluctuations may be correlated with largescale climatic forcing (Koslow et al. 1987). Predator and prey abundance are often correlated (Pepin 1990), suggesting that large year classes in pelagic fish may occur when increases in predator abundance lag behind prey abundance.

Mortality rates are another important determinant of population growth and recruitment success. In practice, growth rates are much easier and cheaper to estimate because they require smaller sample sizes than estimating mortality. Representative specimens have several weeks or months of growth history stored in their otoliths. In addition, growth rate (the inverse of stage duration) and stage mortality may covary because mortality is due largely to predation risks that depend on size. Linkages between growth and mortality rates could be evaluated empirically if sufficient growth and mortality rate data were available (Butler 1989).

In the future, our assumptions require closer scrutiny. We need to improve the precision and accuracy of estimates of parameter values. Also, field research is required to refine and determine the covariance of vital rates. For example, rapid growth in one stage may confer growth rate advantages in subsequent stages, hasten the onset of maturity and provide additional advantages for evading sources of mortality as indicated by DeAngelis et al. (1993) from their individualbased models. The covariance is also essential for analytical computation of variance of $\lambda$ estimates. This material was not pursued in this paper because we lacked data on covariance (Houllier et al. 1989 , Alvaarez-Buylla \& Slatkin 1991).

Our analyses demonstrate that matrix population models are useful tools for examining population changes which respond to changes of vital rates of certain life stages more readily than to others. Although we do not have contemporaneous sets of vital rates for anchovies and sardines, the results of our analyses provide insight into population changes in these 2 species and help define the future research directions on the vital rates of important life stages. These stages may have a direct impact on the success of recruitment.

Acknowledgements. We thank Drs Larry B. Crowder of North Carolina State University, and John Hunter, Larry Jacobson, Geoffrey Moser, and Barbara Taylor of Southwest Fisheries Science Center for providing valuable suggestions. We also thank 3 referees for their constructive criticisms which improved the focus of the paper. 
Appendix A. Description of matrix A

To construct matrix A (Eq. 1), we used the procedures based on Caswell (1989):

$P_{i}$ and $G_{i}$. Both $P_{i}$ and $G_{1}$ are functions of the survival probability $\left(p_{i}\right)$ and the growth probability $\left(\gamma_{1}\right)$ on a daily basis:

$$
P_{1}=p_{1}\left(1-\gamma_{i}\right)
$$

where $p_{i}$ is computed as

$$
p_{1}=e^{-z_{1}}
$$

and $z$, is the daily instantaneous mortality rate (IMR).

$\gamma_{1}$ is computed as follows, assuming fixed or variable stage duration models

Fixed duration: Duration (days; $d_{1}$ ) in each stage is the same for all individuals. Under the assumption of a stable age distribution $\left[1, p_{1} / \lambda_{1} \ldots,\left(p_{1} / \lambda\right)^{i \alpha_{1}-11}\right]$ within a stage, the growth probability was computed as the proportion of the oldest age group to all age groups:

$$
\begin{aligned}
& \gamma_{1}=\frac{\left(p_{i} / \lambda\right)^{d_{i}-1}}{1+\left(p_{1} / \lambda\right)+\ldots+\left(p_{i} / \lambda\right)^{d_{i}-1}} \\
& \gamma_{1}=\frac{\left(1-p_{i} / \lambda\right)\left(p_{i} / \lambda\right)^{d_{i}-1}}{1-\left(p_{i} / \lambda\right)^{d_{l}}}
\end{aligned}
$$

An iterative procedure was used with an initial guess for $\lambda$ because $\gamma_{1}$ depends on $\lambda$. The iteration stops when the difference of the last $2 \lambda$ s is less than 0.0001

Variable duration: $d_{1}$ within a stage was modelled by a negative binomial distribution with parameters $\gamma_{1}$ and $k_{1}$ :

$$
\operatorname{Pr}\left(d_{1}=x\right)=\left(\begin{array}{c}
x-1 \\
k_{2}-1
\end{array}\right) \gamma_{1}^{k_{1}}\left(1-\gamma_{1}\right)^{x-k_{2}}
$$

for $\mathrm{x}=k_{1}, k_{1}+1, k_{1}+2, \ldots$

where $\gamma_{1}$ is the probability of growing into the next pseudostage (analogous to probability of success) and $k_{1}$ is the number of pseudostages within Stage $i$ (number of successes). In other words, a fish in Stage $i$ is assumed to pass through each of $k$, pseudostages with the growth probability $\gamma_{1} \cdot \operatorname{Pr}\left(d_{1}=x\right)$ gives the probability that a fish in Stage $i$ will pass through all $k$, pseudostages and graduate to Stage $i+1$ in $x$ days. No assumption was imposed on the within-stage age distribution. For $\gamma_{1}=1, \mathrm{P}_{\mathrm{r}}\left(d_{1}=k_{1}\right)=1$. Both $\gamma_{1}$ and $k_{1}$ were computed as functions of the mean and variance of duration, $d_{n}$, that follows a negative binomial distribution.

$$
\gamma_{1}=\frac{1}{\mathrm{CV}_{1}^{2} \bar{d}_{1}+1}
$$

and

$$
k_{1}=\frac{1}{\mathrm{CV}_{i}^{2}+\left(1 / \bar{d}_{i}\right)}
$$

where $C V$, is the coefficient of variation of $d$. The quantity $\bar{d}$, is the average duration for Stage $i$. When the $C V=0$, then $\gamma_{1}=1$ and $k_{1}=d_{1}$, the duration for each stage is fixed as in fixed duration. When $\mathrm{CV}$ increases, $k$ decreases and can be less than 1 . We set 1 as the lower bound for $k$ as $k$ is theoretically the number of pseudostages.

For the matrix model based on variable duration, the computation of $\lambda$ is based on an expanded matrix $\mathbf{A}$. which includes all the pseudostages with dimension equal to $\sum k_{l}$. In the case where $k_{1}=1$, the dimension of the expanded matrix $\mathbf{A}$ is reduced to that of the original matrix $\mathbf{A}$. In Eq. (A.4), the mean values, $\bar{d}_{n}$ are listed in column 6 of Tables $2 \& 4$ and the CVs are listed in Table 1 . Sensitivity analyses were conducted for each of the 2 models (see Appendix B).

$F_{i}$ (fertility). We computed the daily fecundity per fish for Stage $i\left(m_{j}\right)$ as

$$
m_{1}=\left[\sum_{j}\left(f_{j} w_{i j}\right)\right] \times 0.5 / \sum_{j}\left(w_{l j}\right)
$$

where $f_{j}$ is the age-specific fecundity rate (the number of eggs per female of age $j$ per unit time) (Tables $3 \& 5$ ). The weight, $w_{i j}$, is the proportion of fish that are of age $j$ :

$$
W_{1 j}=\exp \left(-z_{1} t_{1,}\right)-\exp \left(-z_{1} t_{2,}\right)
$$

where $t_{1}$ is the beginning age and $t_{2 j}$ is the ending age for the fish of age group $j$.

Caswell (1989) provided the general procedure for computing the stage-specific fertility $\left(F_{1}\right)$ : fertility varies with egg mortality, adult mortality, growth probability, spawning time and the time of census. For anchovies and sardines, plankton surveys are usually conducted continuously throughout the day. If we take stage distribution at the peak spawning time as $n_{f}$ (Eq. 2) and assume fish spawn only at the peak spawning time, the fertility at the sampling time will be surviving eggs (Butler et al. 1993). The $F_{\text {, values }}$ computed in this paper may differ from Butler et al. (1993) because Butler et al. (1993) assumed only 1 survey within 1 time unit.

The peak spawning time is $22: 00 \mathrm{~h}$ for anchovies and $20: 00 \mathrm{~h}$ for sardines. In our case, the time unit is $1 \mathrm{~d}$. If a tow was taken at $01: 00 \mathrm{~h}$, for anchovies $u=3 / 24$ and for sardines $u=5 / 24$. For a census taken at the elapsed time after spawning, $u(0<u<1)$, the stage-specific fertility as a function of time (start) of tow $(u)$ :

$$
\begin{aligned}
E_{1}(u) & =m_{1} p_{1}^{{ }^{D}} \\
& =m_{l} e^{-z_{l} u}
\end{aligned}
$$

We integrated the above equation to obtain an average fertulity for Stage $i\left(F_{1}\right)$ :

$$
\begin{aligned}
F_{1} & =\int_{0}^{1} E_{1}(u) d u \\
& =\frac{m_{1}\left[1-\exp \left(-z_{1}\right)\right]}{z_{1}}
\end{aligned}
$$


Appendix B. Sensitivity indices for vital rates

The basic formula for sensitivity indices for vital rates is

$$
\frac{\partial \lambda}{\partial x}=\sum_{1} \sum_{1} \frac{\partial \lambda}{\partial a_{\eta}} \frac{\partial a_{1 j}}{\partial x}
$$

The elasticity index can be obtained from Eq. (4). The quantity $\partial \lambda \partial a_{1 j}$ was given in Eq. (3). In the following sections, we derived formulas primarily for $\partial \alpha_{i j} / \partial x$ where $x$ are vital rates specifically for our matrix population models. The subscripts for stages are omitted for simplicity.

Fixed duration. Sensitivity to age-specific fecundity $\left(f_{j}\right)$ $\partial \lambda / \partial f_{j i}$ : From Eqs. (A5) \& (A6), we have

$$
\begin{aligned}
\frac{\partial \lambda}{\partial f_{j}} & =\sum_{1} \sum_{k} \frac{\partial \lambda}{\partial a_{i k}} \frac{\partial a_{i k}}{\partial f_{j}}=\sum_{k} \frac{\partial \lambda}{\partial a_{1 k}} \cdot \frac{\partial a_{1 k}}{\partial f_{j}} \\
& =\sum_{k} \frac{\partial \lambda}{\partial F_{k}} \frac{\partial F_{k}}{\partial f_{j}}
\end{aligned}
$$

where

$$
\begin{aligned}
\frac{\partial F_{k}}{\partial f_{j}} & =\frac{\partial F_{k}}{\partial m_{k}} \frac{\partial m_{k}}{\partial f_{j}} \\
& =\frac{p_{1}-1}{\ln \left(p_{1}\right)} \frac{w_{k j}}{\sum w_{k j}}
\end{aligned}
$$

and

$$
\frac{\partial m_{k}}{\partial t_{j}}=\frac{w_{k j}}{\sum_{j} W_{k j}}
$$

Indices $i$ and $k$ refer to stage, and index $j$ refers to age.

Sensitivity to instantaneous mortality rate $\left(z_{i}\right) \partial \lambda / \partial z$ :

$$
\frac{\partial \lambda}{\partial z}=\frac{\partial \lambda}{\partial p} \frac{\partial p}{\partial z}=\frac{\partial \lambda}{\partial p}(-1) \mathrm{e}^{-z}
$$

where $\partial \lambda / \partial p$ is derived as follows:

$$
\frac{\partial \lambda}{\partial p}=\frac{\partial \lambda}{\partial P} \frac{\partial P}{\partial p}+\frac{\partial \lambda}{\partial G} \frac{\partial G}{\partial p}
$$

where

$$
\frac{\partial P}{\partial p}=(1-\gamma)-p \frac{\partial \gamma}{\partial p}
$$

$$
\frac{\partial G}{\partial p}=\gamma+\frac{\partial \gamma}{\partial p}
$$

where $\partial \lambda \partial p$ is computed from Eq. (A3):

$$
\frac{\partial \gamma}{\partial p}=\frac{q^{d-2}}{\left[1-q^{d}\right]^{2} \lambda}\left[\left(1-q^{d}\right)(d-1-q d)+(1-q) q^{d} d\right]
$$

where $q=p / \lambda$

\section{Sensitivity to stage duration $\left(d_{i}\right) \partial \lambda / \partial d$ :}

$$
\begin{aligned}
\frac{\partial \lambda}{\partial d} & =\frac{\partial \lambda}{\partial G} \frac{\partial G}{\partial d}+\frac{\partial \lambda}{\partial P} \frac{\partial P}{\partial d} \\
& =\frac{\partial \lambda}{\partial a_{i+1, i}} \frac{\partial G}{\partial d}+\frac{\partial \lambda}{\partial a_{i . i}} \frac{\partial P}{\partial d}
\end{aligned}
$$

where

$$
\begin{aligned}
\frac{\partial G}{\partial d} & =\frac{\partial}{\partial d} p \gamma \\
& =p \frac{\partial \gamma}{\partial d} \\
\frac{\partial P}{\partial d} & =\frac{\partial}{\partial d} p(1-\gamma) \\
& =-p \frac{\partial \gamma}{\partial d}
\end{aligned}
$$

The quantity $\partial y / \partial d$ is computed from Eq. (A3)

$$
\begin{aligned}
\frac{\partial \gamma}{\partial d} & =\frac{\partial}{\partial d} \frac{(1-q) q^{d-1}}{\left(1-q^{d}\right)} \\
& =q^{d-1} \frac{(q-1) \ln (q)}{\left(1-q^{d}\right)^{2}}
\end{aligned}
$$

where $q=p / \lambda$.

Variable duration: The sensitivities to both age-specific fecundity $\left(f_{1}\right)$ and IMR $\left(z_{1}\right)$ are computed the same way as in fixed duration. The sensitivity to the stage duration $\left(d_{i}\right)$, Eq. (A9), still applies, except the quantity $\partial \lambda / \partial d$ needs to be computed from Eq. (A4):

$$
\frac{\partial \gamma}{\partial \bar{d}}=-\frac{C V^{2}}{\left(C V^{2} \bar{d}+1\right)^{2}}
$$

\section{LITERATURE CITED}

Alvaarez-Buylla $R$, Slatkin M (1991) Finding confidence limits on population growth rates. Trends Ecol Evol 6 (7): 221-224

Barnes JT, Jacobson LD, MacCall AD, Wolf P (1992) Recent population trends and abundance estimates for the Pacific sardine Sardinops sagax. CalCOFI Rep 33:60-75

Beyer JE (1989) Recruitment stability and survival - sumple size-specific theory with examples from the early life dynamics of marine fish. Dana Rep 7:45-147

Blythe SP, Nisbet RM, Gurney WSC (1984) The dynamics of population models with distributed maturation periods. Theor Populat Biol 25:289-311

Butler JL (1987) Comparison of the early life history parameters of Pacific sardine and northern anchovy and implications for species interactions. PhD thesis, Univ California, San Diego 
Butler JL (1989) Growth during the larval and juvenile stages of the northern anchovy, Engraulis mordax, in the California Current during 1980-84. Fish Bull US 87:645-652

Butler JL, Smith PE, Lo NCH (1993) The effect of natural variability of life-history parameters on anchovy and sardine populations. CalCOFI Rep 34:104-111

Caswell H (1989) Matrix population models: construction, analysis and interpretation. Sinauer Associates, Inc, Sunderland, MA.

Crouse DT, Crowder LB, Caswell H (1987) A stage-based population model for loggerhead sea turtles and implications for conservation. Ecology 68(5):1412-1423

DeAngelis DL, Rose DA, Crowder LB, Marschall EA, Lika D (1993) Fish cohort dynamics: application of complementary modeling approaches. Am Nat 142:604-622

Deriso $R$ (1993) A report on integrated stock assessment of Pacific sardine, Appendix 2. In: Hester FJ (ed) Project report on Pacific sardine (Sardinops sagax) resource research, 1991/1992 phase III. California Seafood Council. Santa Barbara

Houde ED, Zastrow CE (1993) Ecosystem- and taxon-specific dynamic and energetics properties of larval fish assemblages. Bull mar Sci 53(2):290-335

Houllier F, Lebreton JD, Pontier D (1989) Sampling properties of the asymptotic behavior of age- or stage-grouped population models. Math Biosci 95:161-177

Hunter JR, Lo NCH, Leong RHH (1985) Batch fecundity in multiple spawning fishes. In: Lasker $\mathrm{R}$ (ed) An egg production method for estimating spawning biomass of pelagic fish: application to the northern anchovy. NOAA Tech Rep NMFS 30, p 67-78

Huppert DD, MacCall AD, Stauffer GD (1980) A review of technical issues in the anchovy management plan. SWFSC Admin Rep, La Jolla, CA, LJ-80-12

Jacobson LD, Lo NCH (1992) Spawning biomass of the northern anchovy in 1992. Administrative report LJ-92-24, Southwest Fisheries Science Center, National Marine Fisheries Service, La Jolla, CA.

Koslow JA, Thompson KR, Silvert W (1987) Recruitment to northwest Atlantic cod and haddock stocks: influence of stock size and climate. Can J Fish Aquat Sci 44:26-39

Lasker R (1985) An egg production method for estimating spawning biomass of pelagic fish: application to the northern anchovy, Engraulis mordax. NOAA Tech Rep NMFS 36

Lefkovitch LP (1965) The study of population growth in organisms grouped by stages. Biometrics 21:1-18

This article was submitted to the editor
Lo NCH (1983) Re-estimation of three parameters associated with anchovy egg and larval abundance; temperature dependent incubation time, yolk-sac growth rate and egg and larval retention in mesh nets. NOAA-TM-NMFSSWFC-31, Southwest Fisheries Center, National Marine Fisheries Service, National Oceanic and Atmospheric Administration, US Department of Commerce, La Jolla, CA, p 1-33

Lo NCH (1986) Modeling life-stage-specific instantaneous mortality rates, an application to northern anchovy, Engraulis mordax, eggs and larvae. Fish Bull US 84: $395-407$

MacCall AD (1979) Population estimates for the waning years of the Pacific sardine fishery. CalCOFI Rep 20:72-82

MacCall AD (1980) The consequence of cannibalism in the stock-recruitment relationship of planktivorous pelagic fishes such as Engraulis. In: Sharp G (ed) Workshop on the effects of environmental variation on the survival of larval pelagic fishes. UNESCO, Intergovernmental Oceanographic Commission, Lima, Peru, Workshop Report 28:201-220

Megrey BA (1989) Review and construction of age-structured stock assessment models from theoretical and applied points of view. Am Fish Soc Symp 6:8-48

Methot RD (1989) Synthetic estimates of historical abundance and mortality for northern anchovy. Am Fish Soc Symp 6 : $66-82$

Pepin P (1989) Using growth histories to estimate larval fish mortality rates. Rapp P-v Réun Cons int Explor Mer 191:324-329

Pepin P (1990) Biological correlates of recruitment variability in North Sea fish stocks. J Cons int Explor Mer 47:89-98

Pepin P (1991) Effect of temperature and size on development, mortality, and survival rates of the pelagic life history stages of marine fish. Can J Fish Aquat Sci 48:503-518

Rice JA, Miller TJ, Rose KA, Crowder LB, Marschall EA, Trebitz AS, DeAngelis DL (1993) Growth rate variation and larval survival: inferences from an individual-based size-dependent predation model. Can J Fish Aquat Sci 50:133-142

Smith PE (1985) Year-class strength and survival of O-group clupeoids. Can J Fish Aquat Sci 42(Suppl 1):69-82

Smith PE. Lo NCH, Butler JL (1992) Variation of life stage duration and survival parameters as related to interdecadal population variability in Pacific sardine. CalCOFI Rep 33: $41-49$

Zweifel JR, Lasker R (1976) Prehatch and posthatch growth of fishes - a general model. Fish Bull US 74(3):609-621

Manuscript first received: July 26, 1994

Revised version accepted: May 3, 1995 